\title{
Pretreatment of urban wastewaters in a hydrolytic upflow digester
}

\author{
Pablo Ligero, Alberto Vega and Manuel Soto* \\ Departamento de Química Física e Enxeñería Química I. Universidade da Coruña. Campus da Zapateira s/n, 15071 A Coruña, \\ Galiza (España)
}

\begin{abstract}
Domestic wastewater was fed continuously to a laboratory-scale upflow digester operated at short hydraulic retention times (HRT $<4 \mathrm{~h}$ ). The digester acts as a system for sedimentation and hydrolysis of suspended solids (SS) and for acidification of solubilised substances. Optimum results were obtained at an HRT of $2.3 \mathrm{~h}$. Over $60 \% \mathrm{SS}$ are retained in the digester and hydrolysed. Average influent SS content is $230 \mathrm{mg} / \ell$, whereas effluent SS is $90 \mathrm{mg} / \ell$. Effluent SS concentrations shows very stable behaviour, varying little with influent concentration, as with HRT. Retention and hydrolysis of SS causes an increase in volatile fatty acid (VFA) concentration, from about $20 \mathrm{mg} / \ell$ in the influent to above $100 \mathrm{mg} / \ell$ in the effluent, also contributing toward soluble fraction

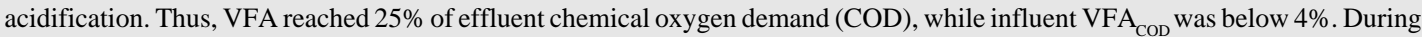
the process, a reduction in domestic wastewater COD of between 30 and $40 \%$ was observed.
\end{abstract}

\section{Nomenclature}

COD

HRT

OLR

SS

VSS

SRT

VFA

VFA $_{\mathrm{COD}}$

HUSB
Chemical oxygen demand $\left(_{\mathrm{t}}\right.$ : total, : soluble).

Hydraulic retention time

Organic load rate

Suspended solids

Volatile suspended solids

Solids retention time

Volatile fatty acids

Volatile fatty acids expressed as COD

Hydrolytic upflow sludge bed (anaerobic digester)

\section{Introduction}

Anaerobic and aerobic treatments constitute two major processes for biological purification of wastewaters and biodegradable organic wastes. Anaerobic digestion is very favourable in terms of energy due to the fact that aeration is not necessary and that biogas is produced which could be used at the same plant as an energy source, allowing in many cases for the autonomy or self-sufficiency of the treatment plant. Another major advantage is that sludge is generated in much lower amounts than those obtained with aerobic processes. As a result, energy and sludge management costs are reduced, making anaerobic digestion the most frequently used biological system for treatment of waste effluents with mediumand high-organic loads (Lettinga et al, 1993).

Moreover, during the 1980s and especially during the 1990s some research groups paid attention to the development of anaerobic digestion for application in the treatment of low concentration effluents (Jewell, 1987; Sanz and Fdz.-Polanco, 1990; Lettinga et al., 1993; Vieira et al., 1994; Kato, 1994). The principal application of anaerobic digestion in urban wastewater treatment consists of the utilisation of single-step methanogenic digesters for organic load removal (Ruiz et al, 1998).

* To whom all correspondence should be addressed.

푱34-981-167000; fax 34-981-167065; e-mail: sotoc@udc.es

Received 30 August 2000; accepted in revised form 15 February 2001.

In the case of urban waste effluents, some authors have reported 30 to $60 \%$ reductions in operating costs as a result of introducing one or more anaerobic steps in treatment systems (Schelinkhout, 1993; Alaerts et al., 1993; Wang, 1994). However, further research on the process and better technological development are necessary to consolidate this technology.

Another option is the separation of phases, in which wastewater undergoes a pre- hydrolysis-acidification step before anaerobic digestion. Some advantages of the direct hydrolytic pretreatment of domestic wastewaters are the following (Wang, 1994; Gonçalves et al, 1994):

- removes an elevated percentage of SS, substituting the primary settler at a similar HRT

- stabilises the sludge, totally or partially

- increases the biodegradability of the remaining COD

- favours the subsequent biological elimination of nutrients $(\mathrm{N}, \mathrm{P})$

- avoids or reduces bulking in the activated sludge process.

To achieve the separation of phases, raw wastewater is fed into an upflow sludge bed reactor, in which the HRT is sufficiently reduced, thereby avoiding the conversion of certain organic fractions into methane. The SS settle in the digester where they remain for a longer period of time than the liquid (SRT, higher than HRT), forming a sludge bed, where some soluble substances are also adsorbed. In this way, both the particulate and the soluble organic matter that are retained can undergo solubilisation and fermentation.

The influence of different variables, such as wastewater characteristics, type of digester, mixing mechanism, HRT and SRT on this process is not yet well understood. The objective of this study was to determine the conversion during the hydrolytic pretreatment of actual urban wastewater, in a system operating at an elevated SRT and at different HRTs. 


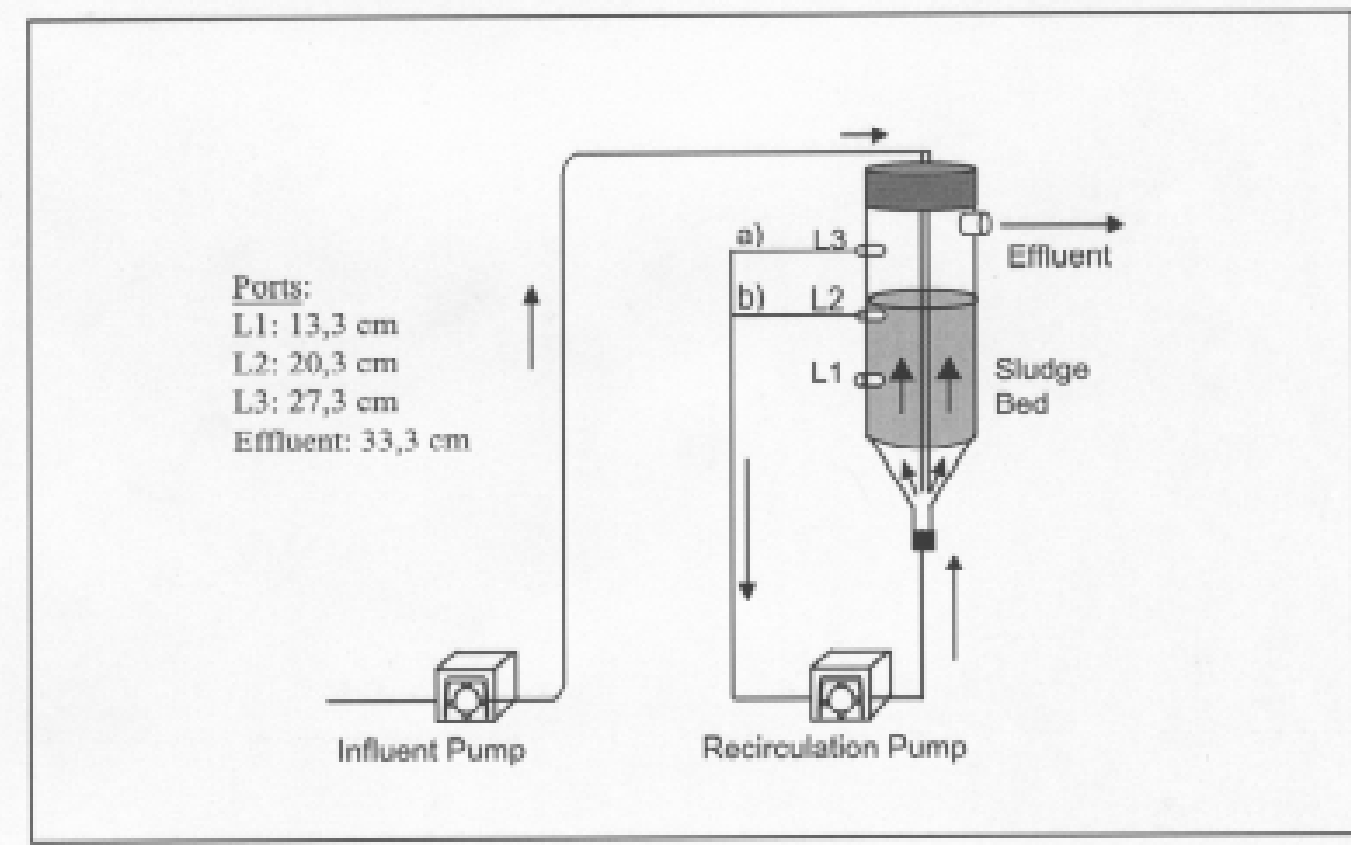

\section{Figure 1 \\ Schematic \\ representation of the digester utilised}

\begin{tabular}{|l|c|c|c|c|l|}
\hline \multicolumn{5}{|c|}{ TABLE 1 } \\
Operation periods of the hydrolytic digester and proposed objectives \\
\hline Phase & Period & Days & $\begin{array}{c}\text { Duration } \\
\text { (d) }\end{array}$ & $\begin{array}{c}\text { HRT } \\
\text { (h) }\end{array}$ & Observations \\
\hline Phase I & & 0 & & & Start up \\
Start-up & Ia & $1-15$ & 15 & 4.5 & Recirculation optimisation and \\
& Ib & $16-34$ & 19 & 3.7 & sludge bed stabilisation \\
& Ic & $35-49$ & 15 & & \\
\hline Phase II & & & & & \\
Operation at & IIa & $50-85$ & 36 & 4.4 & Steady state \\
4.4 h HRT & IIb & $86-125$ & 40 & 4.5 & Steady state \\
& IIc & $126-208$ & 83 & - & Pause (no feed supplied) \\
& IId & $209-225$ & 17 & 4.5 & Restart up \\
\hline Phase III & IIIa & $226-308$ & 80 & 3.5 & HRT change and adaptation \\
Operation at & IIIb & $309-343$ & 35 & 3.4 & Adaptation \\
3.4 h HRT & IIIc & $344-443$ & 100 & 3.4 & Steady state \\
& IIId & $444-495$ & 52 & 3.5 & Steady state \\
& IIIe & $496-512$ & 17 & 3.6 & Steady state \\
\hline Phase IV & & & & & \\
Operation at & IV & $513-574$ & 62 & 2.2 & Steady state \\
2.2 h HRT & & & & & \\
\hline
\end{tabular}

\section{Materials and methods}

\section{Analytical methods}

Determination of SS, VSS, COD (total), COD (soluble), fats, phosphates and sulphates was carried out according to Standard Methods (1985). Total Kjeldahl nitrogen (TKN) was determined by sample digestion with sulphuric acid and selenium reagent, then, using a Kjeldahl apparatus for distillation and titration of samples with hydrochloric acid. Ammonia was determined by using an ion-selective electrode. Biogas composition was analysed chromatographically (HP 5890 serie II), using a thermal conductivity detector (Standard Methods, 1985).

\section{Wastewater}

Urban wastewater was collected directly from a main sewer of the city of A Coruña (Galiza, Spain). Wastewater samples were passed through a $1 \mathrm{~mm}$ sieve, in order to remove gross solids. The feedstock was kept at $4^{\circ} \mathrm{C}$, and renewed twice weekly. Wastewater charac- 
teristics varied depending on the time of year, and especially on the amount of rainfall, since samples came from a non-separative sewer system. For this reason, sample collection was avoided on days of heavy rainfall.

\section{Description of the laboratory digester}

A $2 \ell$-active volume reactor, shown in Fig. 1 , was constructed of plexiglass, having a height of $44 \mathrm{~cm}$ and an internal diameter of $8 \mathrm{~cm}$. The main body was cylindrical with a conical bottom. Feed supply was carried out by means of a tube leading the influent to the cone centre at the bottom of the reactor, circulating upward through the sludge blanket. The reactor was equipped with an internal recirculation system, for the homogenisation of the sludge blanket and to favour wastewater-sludge contact.

Digester height, and therefore, volume, was changed during the study, in order to vary HRT while maintaining a constant influent flow. The recirculation flow was connected in two different positions, as indicated in Fig. 1:

- above the sludge blanket level (a), recirculating only supernatant

- below the sludge blanket level (b), recirculating sludge.

\section{Inoculum}

The reactor was inoculated with anaerobic sludge originated from a methanogenic digester used to treat effluents from a cannedfoods industry at industrial scale. An inoculum volume of $800 \mathrm{~m} \ell$ was used, with a concentration of $13.6 \mathrm{~g} \mathrm{SS} / \ell$ and $11.1 \mathrm{~g}$ VSS$/ \ell$. The methanogenic activity of the inoculum was $0.18 \mathrm{~g} \mathrm{COD}_{\mathrm{CH} 4} / \mathrm{g} \mathrm{VSS} \cdot \mathrm{d}$ at $20^{\circ} \mathrm{C}$.

\section{Operational strategy}

Reactor operation was divided into four periods or phases (Phases $I$ to $I V$ ) which were subdivided into shorter periods (Table 1). The phases differed fundamentally in the HRT applied: Phase $I, 4.0 \mathrm{~h}$ (start-up); Phase II, $4.4 \mathrm{~h}$; Phase $I I I, 3.4 \mathrm{~h}$ and Phase $I V, 2.2 \mathrm{~h}$. A constant feed flow rate was maintained throughout the operation, thus the different HRT values were obtained by varying digester volume and active height. The active reactor volume in each phase was $2.00 \ell$ (Phases $I$ and $I I$ ), $1.75 \mathrm{~L}$ (Phase $I I I$ ) and $1.15 \mathrm{~L}$ (Phases $I V$ and $V$ ), and the active reactor height was $44.0 \mathrm{~cm}$ (Phases $I$ and II), $38.5 \mathrm{~cm}$ (Phase III) and $25.3 \mathrm{~cm}$ (Phase IV).

Table 1 presents the operational characteristics in each period, as well as the proposed objectives. In Phase $I$, during periods $I a-I c$, the system was started up by selecting an adequate recirculation configuration, in order to achieve correct mixing of digester content, and to develop a sludge with appropriate characteristics for the system. Periods $I I a$ and $I I b$ can be considered to be steady state, and were used to determine the operational characteristics of the digester at an HRT of $4.4 \mathrm{~h}$. Later, the HRT was gradually reduced, operating at each period long enough until achieving steady state operation.

\section{Results}

Figure 2 shows the results of the analyses performed on the reactor influent and effluent, while Fig. 3 presents the corresponding conversions reached, in terms of total and soluble COD removal, SS and VSS, and generation of volatile fatty acids. These same parameters are presented in Table 2 as averages for each period.

\section{Start-up}

The start-up process took place from Days 1 to 49 of operation. During this time different recirculation positions and flow were tested in order to obtain a homogeneous and stable sludge bed.

The upflow velocity produced by the influent flow was $0.9 \mathrm{~m} / \mathrm{h}$, constant throughout the different phases. In periods $I a$ and $I b$, recirculation was maintained connected in position $a$ ) (Fig. 1) recirculating only supernatant. Operation was initiated with continuous recirculation, producing a total upflow velocity of $2.4 \mathrm{~m} / \mathrm{h}$ inside the reactor during period $I a$.

Digester operation was initiated with elevated levels of SS and 

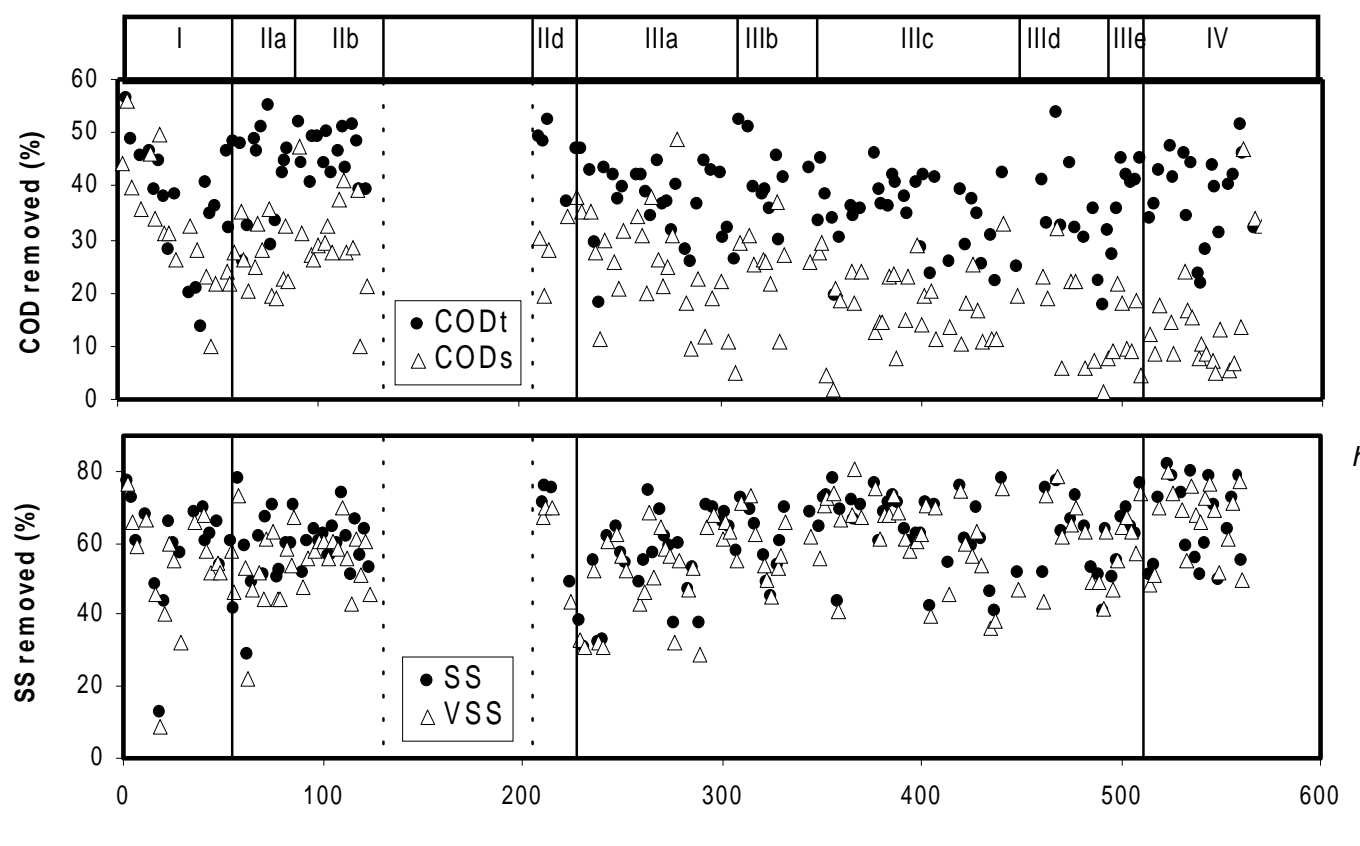

Figure 3

$C O D$ and $S S$

removal for the hydrolytic digester

TIME (days)

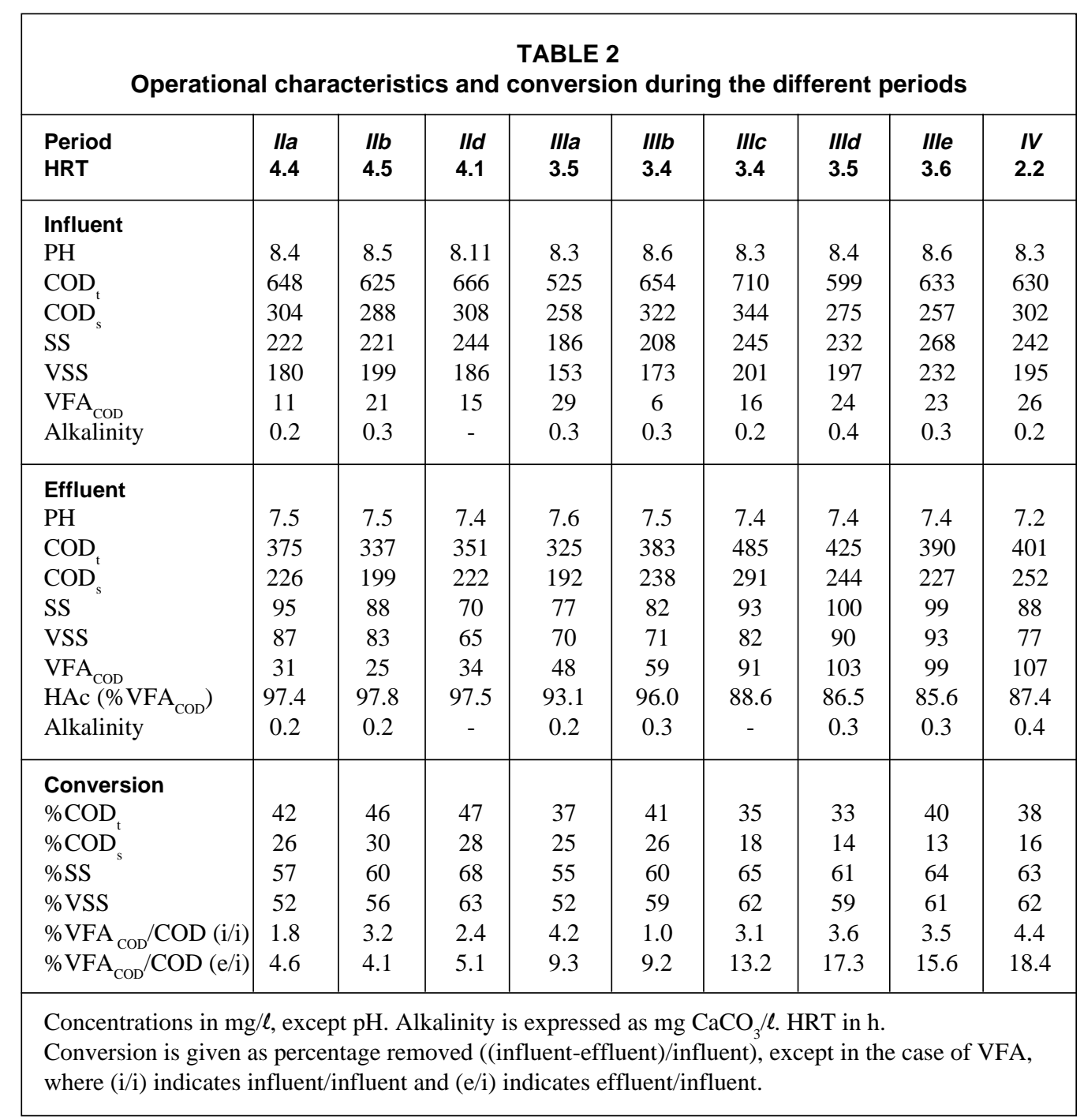


VSS removal, 68 and $67 \%$, respectively. Furthermore, $\mathrm{COD}_{t}$ and $\mathrm{COD}_{\mathrm{s}}$ removal (53 and 44\%) were higher than expected. This indicated that during the first days of operation the reactor clearly acted as a settling system and in addition, methanogenic bacteria introduced by the inoculum removed soluble COD. However, this removal was reduced progressively in the first $15 \mathrm{~d}$ of operation at high upflow velocities. During period $I a$, the sludge bed became compact and the formation of preferential pathways was observed, which explains the sudden fall in efficiency upon restricting wastewater-biomass contact.

In view of this situation, the upflow velocity was reduced. From period $I a$ onwards, the recirculation was performed intermittently for $15 \mathrm{~min}$ per 75 -min cycle. Thus, the resulting upflow velocity was $0.9 \mathrm{~m} / \mathrm{h}$ when the recirculation was disconnected, and $2.4 \mathrm{~m} /$ $\mathrm{h}$ during the short recirculation periods. A slight recovery was observed in the efficiency of SS retention (from Day 15 onwards, Period $I b$ ), but was insufficient for water-sludge contact improvement: the sludge continued to become compact, and the preferential pathways remained. This behaviour suggests that effluent liquid (sludge bed supernatant) recirculation was not sufficient for obtaining a homogeneous sludge bed.

We opted to modify the recirculation position and to recirculate the sludge directly to achieve homogenisation. On Day 34, recirculation was changed from position $a$ ) to position $b$ ), as shown in Fig. 1, and maintained until the end of the study. Intermittent recirculation (15-min periods for each 75-min cycle) in this new position, resulted in adequate mixing and homogenisation of the sludge bed.

\section{Steady state operation at $4.4 \mathrm{~h} \mathrm{HRT}$}

During the operation periods after Day 50, the digester showed adequate behaviour in terms of homogenisation of the sludge bed, and the different conversion parameters were progressively becoming stabilised. Thus, Periods $I I a$ and $I I b$ could be considered at steady state as far as the different properties of the system are concerned, but a slight variation in the total amount of sludge in the digester during these periods was observed. This implies a variation in SRT.

The results obtained in Periods $I I a$ and $I I b$ are representative of digester operation at an HRT of $4.4 \mathrm{~h}$. These results (Table 2) indicate good SS retention, and reflect that the system acted as a hydrolysis-acidification reactor, in which significant removal of easily biodegradable soluble organic matter still exists (probably due to the conjunction of the different biochemical processes taking place, among them conversion to methane). Thus, VFA concentration was still reduced, reaching less than $5 \%$ of influent COD.

\section{Change from 4.4 to $3.4 \mathrm{~h} \mathrm{HRT}$}

Phase III was initiated on Day 226 with operation at an HRT of 3.4 h. Periods III $a$ and IIIb correspond to the transition to the new operational conditions. The percentage of soluble COD removal was slightly reduced during $I I I a$ and $I I I b$ as compared to previous periods, decreasing more abruptly in periods IIIc, IIId and IIIe, corresponding to steady state operation at an HRT of $3.4 \mathrm{~h}$. Therefore, HRT influence on net accumulation of effluent VFA is apparent immediately. Effluent $\mathrm{VFA}_{\mathrm{COD}}$ percentage, over total influent COD, changed from 5 to $9 \%$ from Period IId to III . During Period $I I I b$, the situation was very similar. Moreover, acid accumulation increased even more in the periods to follow (IIIcIIIe).

\section{Steady state operation at $3.4 \mathrm{~h} \mathrm{HRT}$}

As indicated, Periods IIIc, IIId and IIIe could be considered at an HRT of $3.4 \mathrm{~h}$ as operating at steady state. Compared to operation at an HRT of $4.4 \mathrm{~h}$, clearly an improvement in the hydrolyticacidogenic behaviour of the reactor was observed, acidification increased until a range of 13 to $17 \%$ for the $\mathrm{VFA}_{\mathrm{COD}} / \mathrm{COD}_{\mathrm{t}}$ effluent/ influent ratio (Table 2) was reached, whereas soluble COD removal was below $20 \%$, and suspended solids elimination remained above $60 \%$.

During these periods, the acetic acid contribution to VFA, on a COD basis, fell from values above $90 \%$ to within 86 to $88 \%$ (Table 2).

\section{Operation at an HRT of $2.2 \mathrm{~h}$}

On Day 512, HRT was reduced from 3.4 to $2.2 \mathrm{~h}$ to study the digester behaviour at an even shorter HRT (Phase $I V$ ). The system responded positively, maintaining an elevated SS removal percentage (63\%) and reaching VFA concentrations of about 115 $\mathrm{mg}$ COD/l. This suggests that close to $20 \%$ of total influent COD is found as VFA in the effluent.

\section{Discussion}

Previous studies that could be used as a reference to compare the results of the work presented here are scarce. Gonçalves et al. (1994) obtained elevated SS elimination levels (above 69\%) at upflow velocities of below $1.5 \mathrm{~m} / \mathrm{h}$, and optimum acidification results at an HRT of $2.8 \mathrm{~h}$ and at a temperature of $20^{\circ} \mathrm{C}$, with a fermentation rate of $0.17 \mathrm{mg} \mathrm{HAc} / \mathrm{mg}$ influent $\mathrm{COD}_{\mathrm{t}}$. About $60 \%$ of the VFA produced is a result of soluble fraction fermentation, the remaining $40 \%$ corresponding to solubilisation of insoluble organic material (VSS). In the above-mentioned study, acetic acid always reached levels of above $80 \%$ of COD corresponding to VFA, whereas $\mathrm{COD}_{\mathrm{t}}$ elimination was below $25 \%$, and $\mathrm{COD}_{\mathrm{s}}$ increased.

In other work, Wang (1994) achieved SS elimination levels of $83 \%$ and $\mathrm{COD}_{\mathrm{t}}$ elimination levels of $43 \%$ at an HRT of $2.5 \mathrm{~h}$. Similarly, Wang evaluated the influence of influent COD levels on efficiency (\%COD eliminated) in a hydrolytic upflow sludge blanket (HUSB) anaerobic reactor, observing that the system absorbed increases in influent COD very well, with little variation in effluent COD.

In the present study the upflow velocity applied was $0.94 \mathrm{~m} / \mathrm{h}$, being within the optimum value indicated by Gonçalves et al. (1994), whereas the optimum HRT was the lowest studied, $2.2 \mathrm{~h}$. Under these conditions, SS elimination was $63 \%, \mathrm{COD}_{\mathrm{t}}$ removal $38 \%$, at a time when soluble COD was reduced by $17 \%$. The retention capacity of SS was lower than in the two studies referred to, perhaps due to a lower sludge bed height which would limit its filtration capacity. Generation rate of acids increased as HRT decreased, until reaching $0.18 \mathrm{mg} \mathrm{VFA}_{\mathrm{COD}} / \mathrm{mg} \mathrm{COD}_{\mathrm{t}}$ fed to the digester, very similar to the rate obtained by Gonçalves et al. (1994). The percentage of VFA as acetic acid was always above $85 \%$.

The low acid generation rate at elevated HRT is probably due to the elimination of acids formed by different processes, such as methanogenic respiration, sulphate-reduction or nitrificationdenitrification. Because methane generated in small quantities can leave the system dissolved in the liquid, it was not included in the quantification of biogas generation.

In the studies of Wang (1994), as well as in the present study, the hydrolytic digester was inoculated with digested primary 
sludge. In both cases, canals and preferential pathways were observed in the sludge bed during start-up. Wang resolved this problem by introducing mechanical mixing, while in this study, water to sludge contact was improved by recirculating the sludge instead of recirculating the supernatant. Upon visual observation, the appearances of the inoculated sludge and of the sludge developed in the hydrolytic digester were clearly different. Perhaps, the elevated mineralisation of the inoculum employed, and its elevated density, aided the initial compactness of the sludge blanket. In the present study, these problems did not reappear during the remainder of the experiment. This problem could have been resolved from the beginning by recirculating the actual sludge, or, perhaps, by starting-up without inoculum, and allowing it to develop from influent solids retained in the digester.

The results obtained confirm the importance of direct hydrolytic pretreatment of domestic wastewaters, this being reflected by elevated SS retention and removal, and by increased biodegradability of remaining COD. Thus, anaerobic hydrolysis of domestic wastewater is of great interest for the secondary treatment using the anaerobic pathway (two-stage digestion), as well as for the aerobic pathway with its multiple variations. Furthermore, a greater proportion of easily biodegradable COD favours phosphorus elimination, $0.1 \mathrm{mg} \mathrm{P} / \mathrm{mgVFA}_{\mathrm{COD}}$ (Henze et al., 1995), such that a biological phosphorus removal post-treatment could potentially eliminate all the phosphorus contained in wastewaters.

\section{Acknowledgements}

This work was part of project XUGA10307A97, supported by the "Conselleria de Educación e Ordenación Universitaria (Dirección Xeral de Universidades e Investigación)" of "Xunta de Galicia”.

\section{References}

ALAERTS GJ, VEENSTRA S, BENTVELSEN M and VAM DUIJL LA (1993) Feasibility of anaerobic sewage treatment in sanitary strategies in developing countries. Water. Sci. Technol. 27 (1) 179-186.

GONÇALVES RF, CHARLIER AC and SAMMUT F (1994) Primary fermentatiom of soluble and particulate organic matter for wastewater treatment. Water Sci. Technol. 30 (6) 53-62.

HENZE H, HARREMOES P, JANSENS J and ARVIN E (1995) Wastewater Treatment. Springer-Verlag, New York.

JEWELL W J (1987) Anaerobic sewage treatment. Environ. Sci. Technol. 21 (1) $14-21$.

KATO MT (1994) The Anaerobic Treatment of Low Strength Soluble Wastewaters. Ph.D. Thesis, Agric. Univ. of Wageningen, The Netherlands.

LETTINGA G, DE MAN A, VAM DER LAST ARM, WIEGANT W, VAM KNIPPENBERG K, FRIJNS J and VAM BUUREN JCL (1993) Anaerobic treatment of domestic sewage and wastewater. Water Sci. Technol. 27 (9) 67-73.

RUIZI, SOTO M, LIGEROP, DE VEGA A, VEIGA MC and BLÁZQUEZ $R$ (1998) Performance and biomass characterisation of an UASB digester treating domestic wastewaters at ambient temperature. Water SA 24 (3) 215-222.

SANZ I and FDZ-POLANCO F (1990) Low temperature treatment of municipal sewage in anaerobic fluidised bed reactors. Water Res. 24 (4) $463-469$.

SCHELINKHOUT A (1993) UASB technology for sewage treatment: Experience with a full-scale plant and its applicability in Egypt. Water Sci. Technol. 27 (9) 173-180.

STANDARD METHODS (1985) Standard Methods for the Examination of Water and Wastewater (17 ${ }^{\text {th }}$ edn.), APHA-AWWA-WPCF, Washington.

VIEIRA SMM, CARVALHO JL, BARIJAN FP and RECH CM (1994) Application of the UASB technology for sewage treatment in a small community at Sumare, Sao Paulo State. Water Sci. Technol. 30 (12) 203-210.

WANG K (1994) Integrated Anaerobic and Aerobic Treatment of Sewage. Ph.D. Thesis, Agric. Univ. of Wageningen, The Netherlands. 